\title{
TIME-RESOLVED VOLTAGE BREAKDOWN IN VARIOUS INSULATORS DUE TO 2-MEV ILCTRONS
}

\author{
LeRoy M, Erickson \\ David C. Oakley
}

April 5, 1973

Prepared for US. Atomic Energy Commission under contract No.W-7405-Eng-48
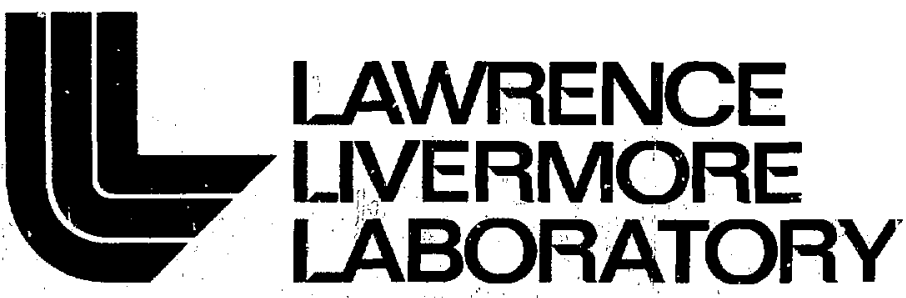

University of California/Livermore 


\section{NOTICE}

"This report was prepured as an account of work sponsored by the United Slates Government. Neither the United States nor the United States Atomic Energy Commission, nor any of theis employees, nor any of thet contractors, sutoontraciors, or thets emplayees, makes any waranty, express or implierl. or assumes any legal llability or reuponsibility for the accuracy, completeness or usctulness of any informution, apparatus, product or process diclosed, or represonts that its use would not infringe privatelyowned rights."

Printed in the United States of America Avallable from

National Technical Information Service

U.S. Department of Commerce 5285 Port Royal Road Springfield, Virginia 22151

Price: Printed Copy $\$$ ₹; Microfiche $\$ 0.95$

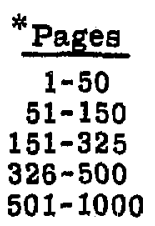

NTIS

Selling Price

$\$ 4.00$

$\$ 5.45$

$\$ 7.60$

$\$ 10.60$

$\$ 13.60$ 
TID-4500, UC-34

Physics

\title{
㢟 \\ LAWFENCE LNERMORE LABOAATOAY \\ Uhivarsity of Caliornia Lwermora, Catfornia $\$ 4550$
}

UCRL-51372

\section{TIME-RESOLVED VOLTAGE BREAKDOWN IN VARIOUS INSULATORS DUE TO 2-MEV ELECTRONS}

\author{
LeF،oy M. Erickson \\ David C. Oakley
}

MS. date: April 5, 1973

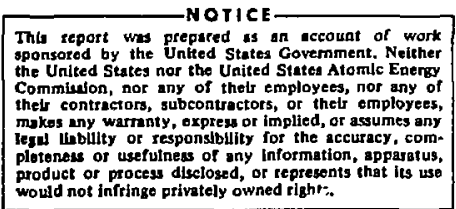

would not inftinge privately owned right: 


\section{Contents}

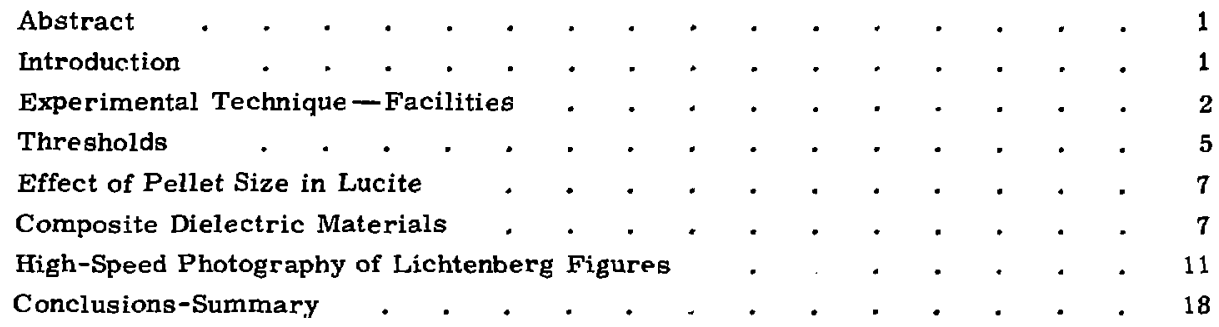




\title{
TIME-RESOLVED VOLTAGE BREAKDOWN IN VARIOUS INSULATORS DUE TO $2-\mathrm{MeV}$ ELECTRONS
}

\begin{abstract}
A pulsed beam of electrons from a 2-MeV Febetron "was injected into several insulating materials and the resultant self-breakdown characteristics of the materials were studied. The materials included lucite, vinyl chloride, polyethylene, Teflon, pyrex, type 815 epoxy, and pyrex glass. The threshold for formation of Lichtenberg figures was established for several of the materials. Highspeed photography was used to observe the figures as they formed in some of the transparent materials, and propagation velocities were established for some exposure levels. Propagation velocities were found to vary as a function of exposure level for those materials and

exposure levels in which we were able to obtain a measurement. Intensity of the main stems of the figures was increased in small pellets of some materials by exposing them in a liquid dielectric bath; that is, electrons deposited in the liquid apparently discharged through the main stems of the pattern in the solid dielectric to a grounded point on the back center of the solid material. It is much more difficult to form Lichtenberg figures in solid dielectrics composed of two separate insulators such as Lucite granules cast in epoxy. The Lichtenberg figur $3 s$ did not cross boundaries between the materials at our exposure levels and conditions.
\end{abstract}

\section{Introduction}

When charged particles aro injected into an insulating material, a charge is built up inside the material at the depth of penetration of the charged particles. If the charge density gets high enough, the voltage gradient exceeds the dielectric strength of the insulator and breakdown occurs in the plane of the deposited charges. The depth of penetration de-

\footnotetext{
* Reference to a company or product name does not imply approval or recommendation of the produc by the University of California or the U.S. Atomic Energy Commission to the exclusion of others that may be suitable.
}

pends upon the eriergy of the incident elertro, beam and the density of the insulati. $g$ material. In lucite, $2-\mathrm{MeV}$ electrons penetrate to a depth of about $3 \mathrm{~mm}$; when about $1 \mu \mathrm{C} / \mathrm{cm}^{2}$ have been deposited, spontaneous breakdown usually occurs forming the destructive breakdown paths in the material known as Lichtenberg figures. If breakdown does not occur spontaneously, it can usually be induced by the application of a mechanical stress (such as striking the material with a grounded center punch).

We studied the formation of these patterns in various insulating materials and 
cumbinations of insulating materials for the purpose of determining the breakdown characteristics of certain materials and combinations of materials.

\section{Experimental Technique-Facilities}

We used a Model 705 Febetron as the electron source. It produces electrons with a nominal energy of $2.1 \mathrm{MeV}$ and a pulse duration of about $50 \mathrm{nsec}$ full width at half maximum (FWHM). Experiments were conducted $61 \mathrm{~cm}$ or farther from the face of the machine. The beam intensity at that point was enhanced by the use of a tapered pipe made from copper screen. The pipe has a $10 \mathrm{~cm}$ diam at the source end and a $5 \mathrm{~cm}$ diam at the experiment end. The beam was fairly uniform over the $5 \mathrm{~cm}$ diam; hovever, with most focus magnet settings there is a hot spot in the center of about $1.5 \mathrm{~cm}$ diam. The beam level is higher in this hot spot than in the surrounding area and the degree of nonuni ormity is a function of focus magnet current. Figure ia is a photograph of the setup showing the copper screen in place and a sample holder

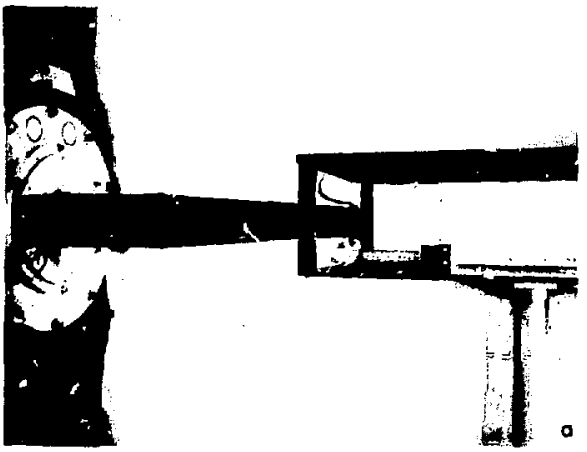

$10 \mathrm{~cm}$ frora the end of the screen. Figure $1 \mathrm{~b}$ is a view of the same flat sample holder with an exposed sample in place. Photographs were taken of the air ionization patterns formed by the beanı under various conditions. Figure 2a shows the beam in air with the screen in place. Figure $2 b$ shows the beam in air with no screen. Figure $2 \mathrm{c}$ shows the bearn in air with the Faraday cup placed $61 \mathrm{~cm}$ away from the face of the screen. Figure 2d indicates the effect of a ground plane extending beyond the screen. To offset this effect, a similar ground plane was placed above the beam. At full focus-magnet current the bear. intensity was measured at about $15 \mu \mathrm{C} / \mathrm{cm}^{2}$ at the end of the screen. Without the screun the beam was measured at $2.5 \mu \mathrm{C} / \mathrm{cm}^{2}$ at the same distance of $61 \mathrm{~cm}$ from the face of the machine.

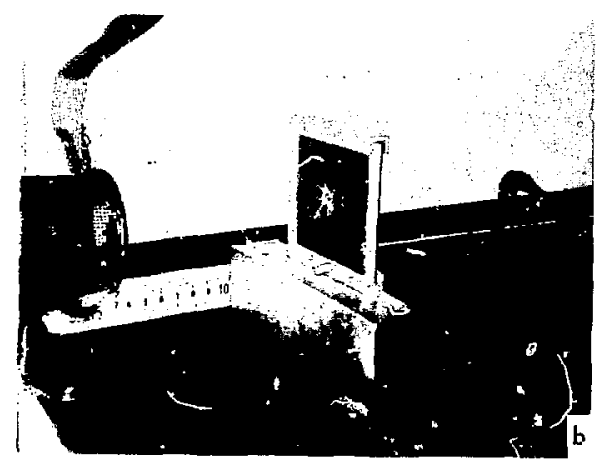

Fig. 1. (a) Exposure setup with flat sample holder at end of screen. (b) Flat sample holder. 

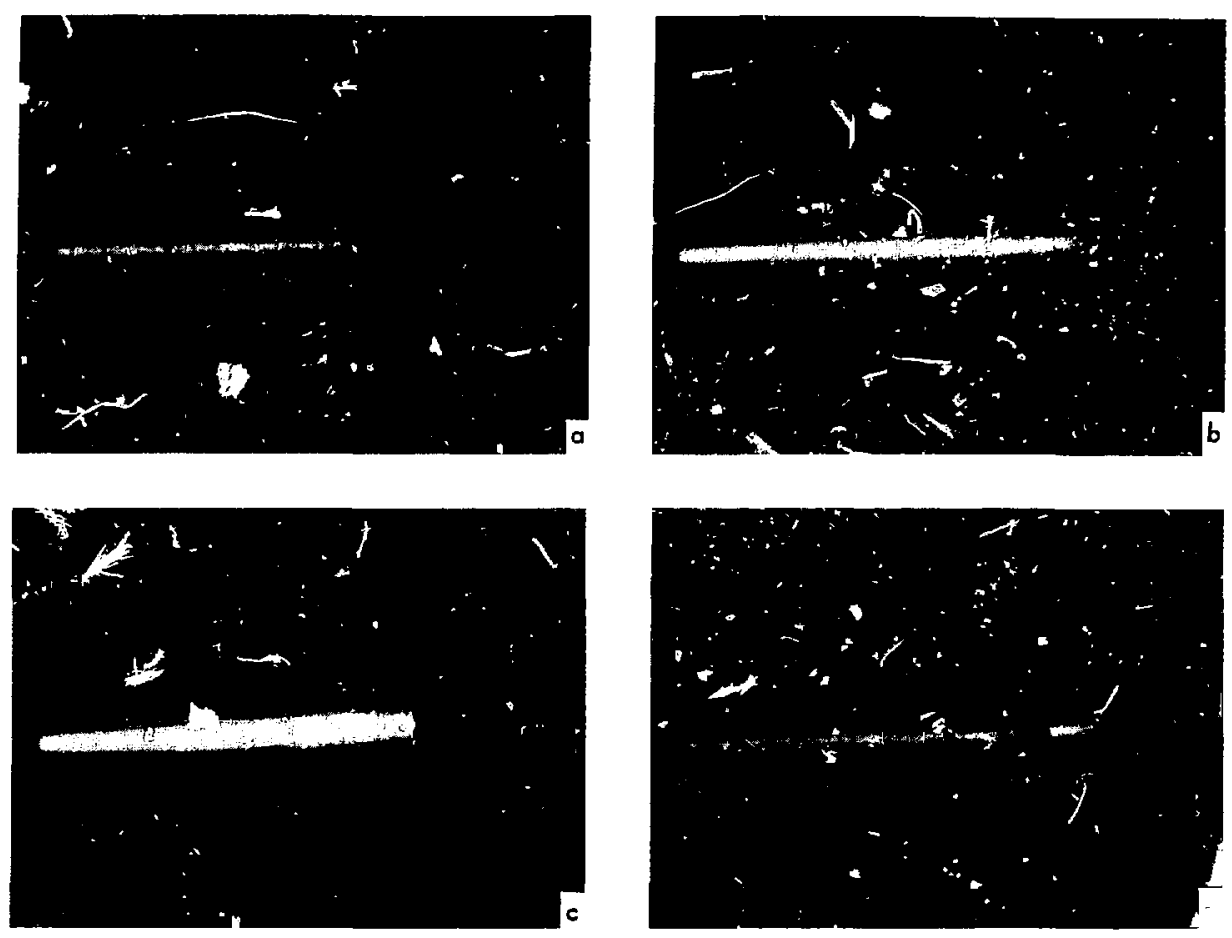

Fig. 2. Febetron beam in air (a) with screen, (b) without screen, (c) without screer: and with Faraday cup in place, (d) showing the effect of a single ground plane beneath the beara.

Beam current measurements were made with a Faraday cup with the output voltage across a $1.0 \Omega$ resistor recorded on an cscilloscor,e with a sweep speed of $20 \mathrm{nsec} / \mathrm{cm}$. The cup consisted of a $5 \mathrm{~cm}$ diam $\times 5 \mathrm{~cm}$ deep beryllium cup mounted inside of a brass housing. The beam was collimated into the cup with openings of $1 \mathrm{~cm}^{2}, 0.5 \mathrm{~cm}^{2}$, or $0.25 \mathrm{~cm}^{2}$. Beam current measurements were made with the $0.5 \mathrm{~cm}^{2}$ collimation; the other sizes were only used to see that the current reading was proportional to collimator size. It was proportional, which lends some credence to the Faraday cup readings. A rough check with a button calorimeter (an $\mathrm{Al}$ button $0.397 \mathrm{~cm}$ diam $\times 0.254 \mathrm{~cm}$ thick with a thermocouple welded on the back) was found to agre e within a factor of two. The thermccouple output was recorded on a strip chart recorder. Backscatter and secondary electron effects with the Fararlay cup were minimized by making the opening into the cup only slightly larger than the collima.* tor size, thus reducing the sciid angle for those electrons.

Exposures were made of $7.5 \times 7.5$ $\times 0.6 \mathrm{~cm}$ pieces of various plastic miterials to establish thresho'd levels for the 


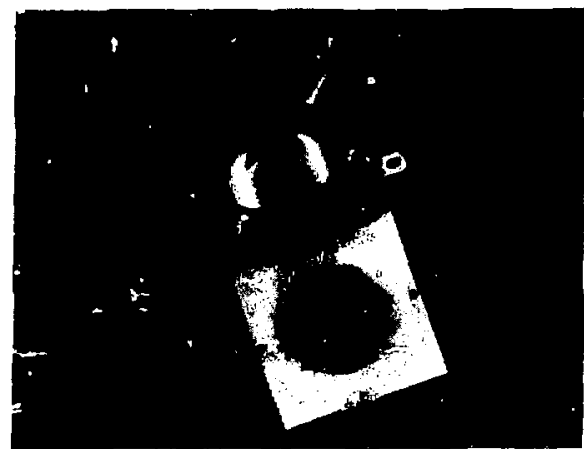

Fig. 3. Sample holder for suspending solid sample in liquid.

formation of Lichtenberg figures. The sample was inserted into a brass holder along with a copper sheet that provided a ground plane behind the sample. The same holder was used to expose lucite pellets of various sizes to determine the effect of pellet size on the pattern. The pellets were mounted in lucite sheets which were then placed in the holder.

A special sample mount was designed to hold a solid sample pellet suspended in a liquid. The pellet was mounted on a "spider" made of fiberglass and provisions were made for either a pointed ground pin or a grounded flat plate in contact with the back surface of the sample. Details of the assembly at shown in Fig. 3.

Table 1 lists the dielectric constants for the various materials used in these experiments. Vaiues in the table were taken from various sources; those for the plastic materials came from data supplied by the manufacturer, the Shell 815 epoxy was measured at LLL, and the values for liquids were taken from Circular 514, National Bureau of Standards.

Tabie 1. Dielectric constants for materials used in experiments.

\begin{tabular}{|c|c|c|c|c|c|}
\hline & \multirow{2}{*}{$\begin{array}{c}\text { Volume } \\
\text { resistivity } \\
\text { (ohm }-\mathrm{cm} \text { ) }\end{array}$} & \multicolumn{3}{|c|}{ Dielectric constant } & \multirow{2}{*}{$\begin{array}{l}\text { Density } \\
\mathrm{g} / \mathrm{cm}^{3}\end{array}$} \\
\hline & & $60 \mathrm{~Hz}$ & $10^{3} \mathrm{~Hz}$ & $10^{6} \mathrm{~Hz}$ & \\
\hline Lucite & $10^{15}$ & 3.5 & 3.0 & 2.2 & $1.18-1.20$ \\
\hline Polyethylene & $10^{16}$ & 2.3 & 2.3 & 2.3 & $0.9-0.93$ \\
\hline Teflon & $10^{18}$ & & 2.1 & & $2.13-2.20$ \\
\hline Nylon & $3 \times 10^{15}$ & 3.8 & & & $1.12-1.15$ \\
\hline Shell 815 epoxy & & & 3.3 & & 1.20 \\
\hline Shell dialax & & 2.2 & & 1.8 & 0.86 \\
\hline Carbon tetracnloride & & 2.23 & & & 1.59 \\
\hline 2-proponal & 18.3 & & & & 0.786 \\
\hline Water & 78.5 & & & & 1.0 \\
\hline
\end{tabular}




\section{Thresholds}

We exposed several insulating materials to determine the threshold for formation of Lichtenberg figures. Beam intensity was varied by a combination of magnet current and distance from the end of the screen to the sample. The beam was measured witl the Faraday cup for each threshold set of conditions. For polyethylene, Teflon, ard lucite, threshold was found to be about $1 \mu \mathrm{c} / \mathrm{cm}^{2}$. Lucite was slightly higher at $1.1 \mu \mathrm{C} / \mathrm{cm}^{2}$. These threshold measurements were made with a ground plane in back of the sample. In most of the plastic materials we studied, if the material is prestressed by deforming it with a pointed object (such as a center punch) then the threshold is considerably lower. We did not attempt to measure this sort of threshold since it is highly dependent on the amount of stress applied.

Radiachromic films were used to measure electron dose as a function of depth of penetration in lucite. The films were $0.002-i n$. thick, and they were supplied, calibrated, and read by EG\&G in Santa Barbara. Films were exposed to the Febetron beam at an intensity of $15 \mu \mathrm{C} / \mathrm{cm}^{2}$, and exposures were made in two ways; (1) a piece of the illm was sandwiched between two 1/4-in, thick slabs of lucite and exposed edge-on, and (2) pieces of the film were sandwiched between lucite sheets with various thicknesses of lucite on the front side. The two approaches were found to yield the same results; however, the edge-on exposure was simpler to analyze.

The solid line curve oi Fig. 4 is the plot of an edge-on exposure of the radia- chrcınic film. The sharp rise in the first $0.2 \mathrm{~mm}$ is in part due to the effect of trying to take densitometer readings at the edge of the exposed film. The peak dose is seen to be at about $2.5 \mathrm{~mm}$ depth. When Lichtenberg figures are formed in lucite with the 2-MeV Febetron beam, they tend to form in a plane at an average depth of about $2.75 \mathrm{~mm}$, or just beyond point of the measured peak electron dose.

The dashed line on Fig. 4 is an ETh.1N calculation of dose vs depth in lucite based on the same $15 \mu \mathrm{C} / \mathrm{cm}^{2}$ incident $2 \mathrm{MeV}$ monoenergetic electron beam. (ETRAN is a Monte Carlo type coupled photon-electron transport code.)

The calculation and the measurement agree surprisingly well to a depth of $2 \mathrm{~mm}$. Beyond that point the code predicts a higher dose than we measured. This is construed to be due in part to the fact that as electrons are deposited they exert a repulsive force on succeeding electrons, and this repulsive force is not taken into account in the ETRAN code. In addition, the ETRAN calculations were based on monoenergetic 2-MeV electrons. We did not attempt to make spectral measurements on the electron beam energy, but the voltage pulse only holds at its peak value for about 0.4 of the 50 nsec full-width half-maximum current pulse. Due to ais factor, as well as air scattering effects, the average electron energy is less than $2 \mathrm{MeV}$. Inclusion of the lower-energy electrons would, we believe, skew the calculated curve into better agreement with the measured values at the larger depths. 


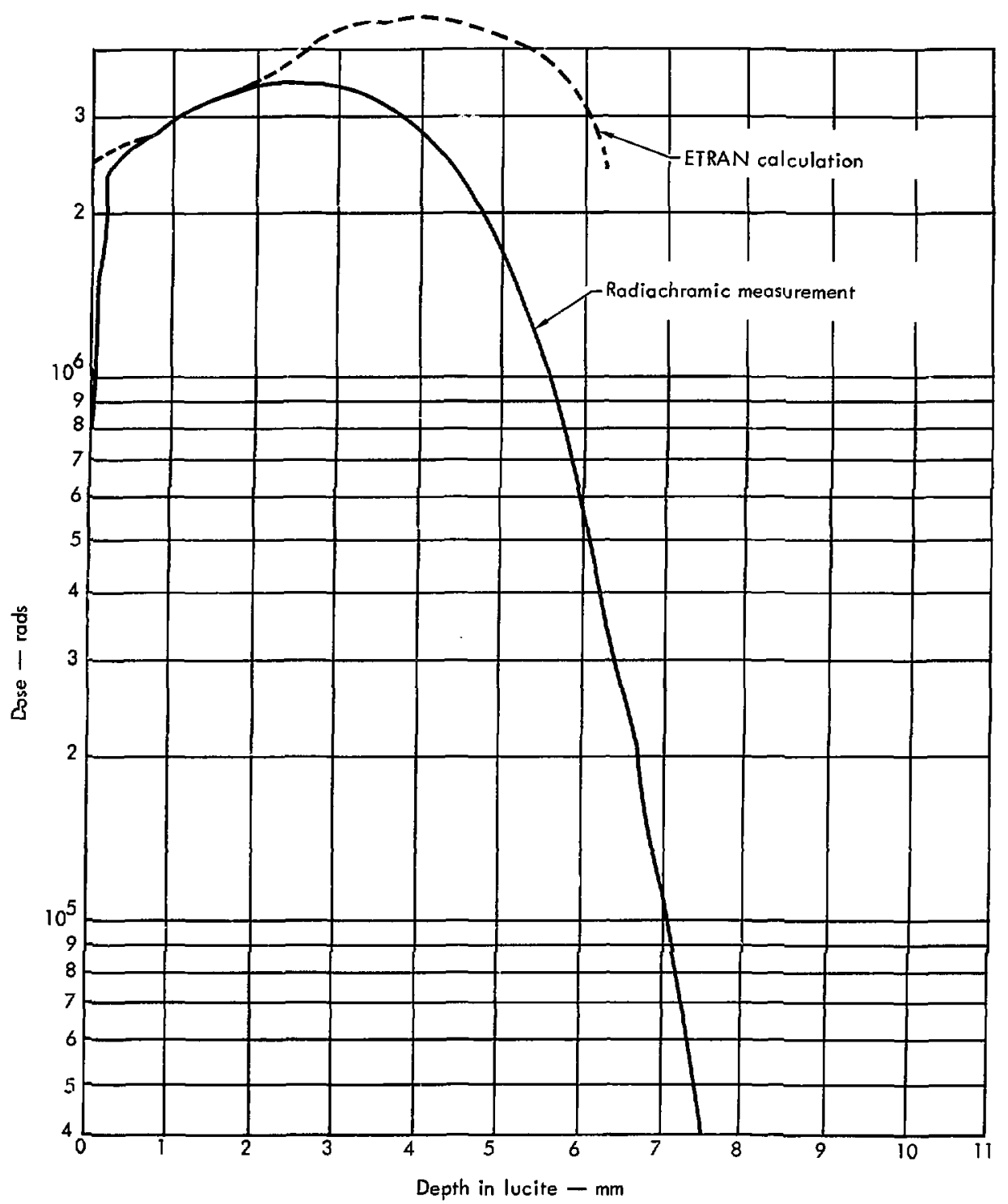

Fig. 4. Dose vs depth in lucite at an incident beam intensity of $15 \mu \mathrm{C} / \mathrm{cm}^{2}$. 


\section{Effect of Pellet Size in Lucite}

Lucite pellets, $0.6 \mathrm{~cm}$ thick and of several diameters, were exposed at the same beam intensity to examine the effect of pellet size on the intensity of the pattern formed. For exposure, the pellets were inserted into holes in $7.5 \times 7.5$ $\times 0.6 \mathrm{~cm}$ pieces of lucite which were then inserted into the holder with the ground plane on the back side of the lucite as before. Exposures were made at a level

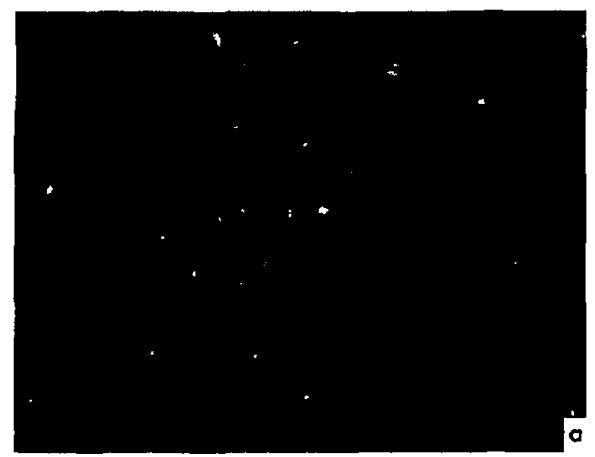

of $2.5 \mu \mathrm{C} / \mathrm{cm}^{2}$. The results of these exposures are shown in the photographs of Figs. $5 a$ and $5 \mathrm{~b}$ from which it appears that, although the number of tracks per unit area is similar in all cases, the main stems or tracks of the figures in the larger pellets are of a larger diameter, and so the patterns appear more intense. Pellets of $0.3 \mathrm{~cm}$ diam did not produce a figure at this beam intensity.

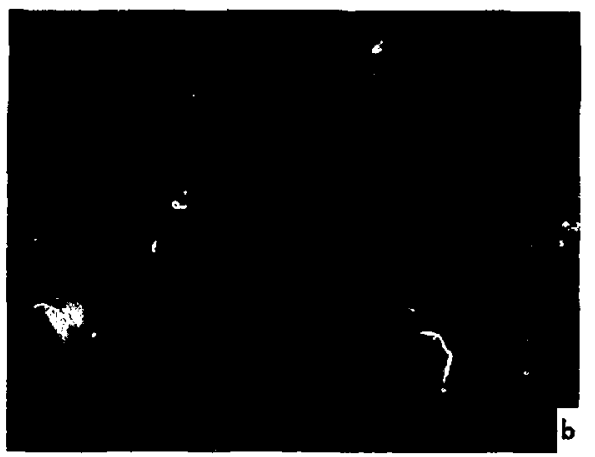

Fig. 5. (a,b) Lichtenberg figures in various size lucite pellets exposed at the same beam intensity.

\section{Composite Dielectric Materials}

We hoped to determine whether the Lichtenberg figures would cross the boundary between two dielectric materials. Our first approach was to simply insert a $1.26-\mathrm{cm}$ diam by $0.6 \mathrm{~cm}$ thick pellet of lucite in a lucite holder. The pellet was dimensioned for a tight fit in the holder. Although figures were formed in both pieces, there were no indications that any figure crossed the boundary. Next the same kind of pellet was glued into the holder with epoxy, and the results were the same as before.

Small lucite pellets (roughly in the form of cubes $2.5 \mathrm{~mm}$ on a side) were cast in an epoxy (Shell Type 815, "D" curing agent) having a dielectric constant of 3.3 at $1000 \mathrm{~Hz}$. The casting was machined into a cylinder of $3.8 \mathrm{~cm}$ diam and $0.6 \mathrm{~cm}$ thick. In two exposures of these composite materials Lichtenberg figures were formed in both materials, but none 
of the patterns were observed to cross the boundary from one material to the other.

Next the $2.5 \mathrm{~mm}$ cube pellets of lucite were poured into a holder designed to hold lizguids (see Fig. 3). Pellets were exposed over a $5-\mathrm{cm}$ diam at a beam intensity of about $5 \mu \mathrm{C} / \mathrm{cm}^{2}$. The pellets were then recovered and examined for Lichtenberg figures. Only about 10 of the pellets showed figures, and these were found in the vicinity of the grounded pin which protruded into the mass of pellets from the rear. A new batch of pellets were then poured into the holder, and the holder was then filled with Shell Dialex transformer oil, which has a dielectric constant of 2.2. Examination of the pellets after exposure showed a large increase in the number of pellets with figures. Approximately 200 pellets were found with patterns, indicating an appreciable enhancement of the effect due to immersion in oil.

The next approach was to place $2.2 \mathrm{~cm}$ diam $\times 0.6 \mathrm{~cm}$ thick lucite pellets in the liquid holder and expose them. The opening into the holder was $5 \mathrm{~cm}$ in diameter, and the beam current was fairly uniform over that area. A grounded sharp point was spring loaded against the back of the pellet to provide a ground return path for the electrons. The front window of the holder was raade of 6-mil mylar. The pellet was mounted on a spider made of fiberglass (see Fig. 3) which stands the pellet off from the mylar, leaving a $0.08 \mathrm{~cm}$ gap to be filled with the fluid. Hence, the beam must traverse the 6-mil mylar and $0.08 \mathrm{~cm}$ of fluid before reaching the pellet.

Figure 6a, b, and $c$ show the patterns formed when the pellets were exposed at a level of $1.5 \mu \mathrm{C} / \mathrm{cm}^{2}$ in air, Shell Dialax transformer oil, and in 2-proponal. Dielectric constants of these liquids are listed in Table 1. The pattern formed in the pellet exposed in air (dry) is shown in
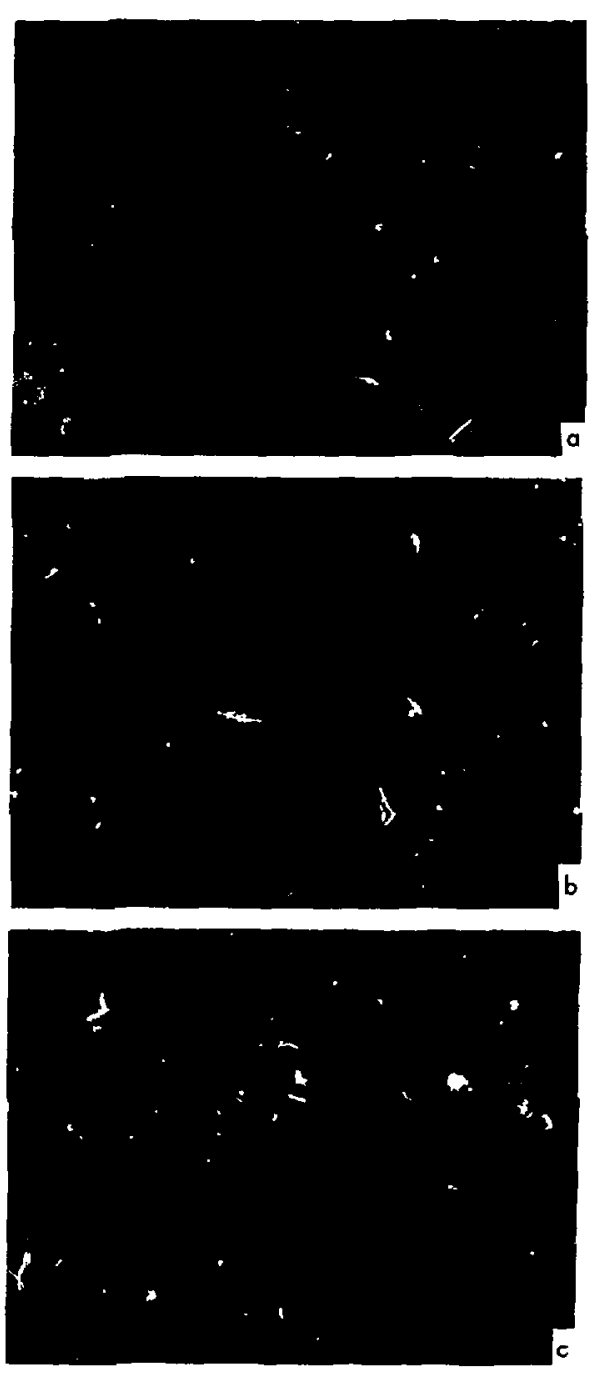

Fig. 6. Lucite pellet exposed (a) in air, (b) in transformer oil, (c) in alcohol. 
Fig. 6a. The pattern has many main stems and they do not extend to the outside radius. One small track in the upper left side of the picture (at 10 o'clock) appears to have formed a discharge into the air through the side of the pellet. Figure $6 \mathrm{~b}$ is a photograph of a pellet exposed in the Shell Dialax oil. Note that many of the main stems extend to the outside edge of the lucite. We may infer from this that we have obtained communication between the two dielectric materials. Tiat is, electrons deposited in the oil have discharged through the oil into the lucite, and along the main stems of the figures in the lucite to the grounded point. Figure $6 \mathrm{c}$ is a photograph of a
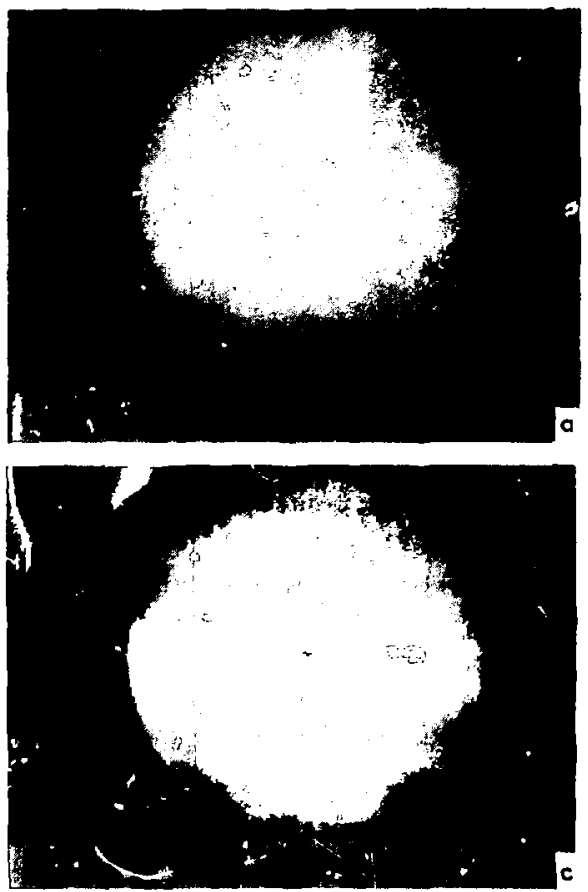

Iucite pellet exposed in 2-proponal (Alc). Its characterisiics are similar to the one exposed in oil; however, while some of the main stems extend to the outside edge, they are less intense there, indicating less electrical communication between the fluid and the lucite.

Similar pellets of polyethylene, (2.2-cm diam $\times 0.6-\mathrm{cm}$ thick) were exposed in the same configuration at a level of $5 \mu \mathrm{C} / \mathrm{cm}^{2}$. Instead of the grounded point, a grounded, spring-loaded flat piate was used behind the pellet to provide a ground return path. Figure $7 a, b$, $c$ and $d$ show the results of these exposures. Of these, the one exposed in 2-proponal appears to have the least
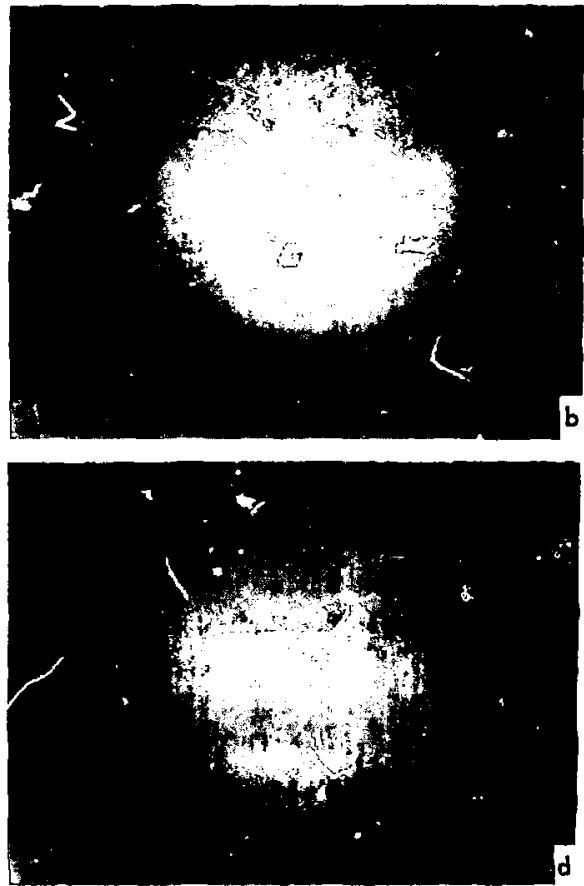

Fig. 7. Polyethylene pellet exposed (a) in air, (b) in transformer oil, (c) in alcohol, (d) in carbon tetrachloride. 

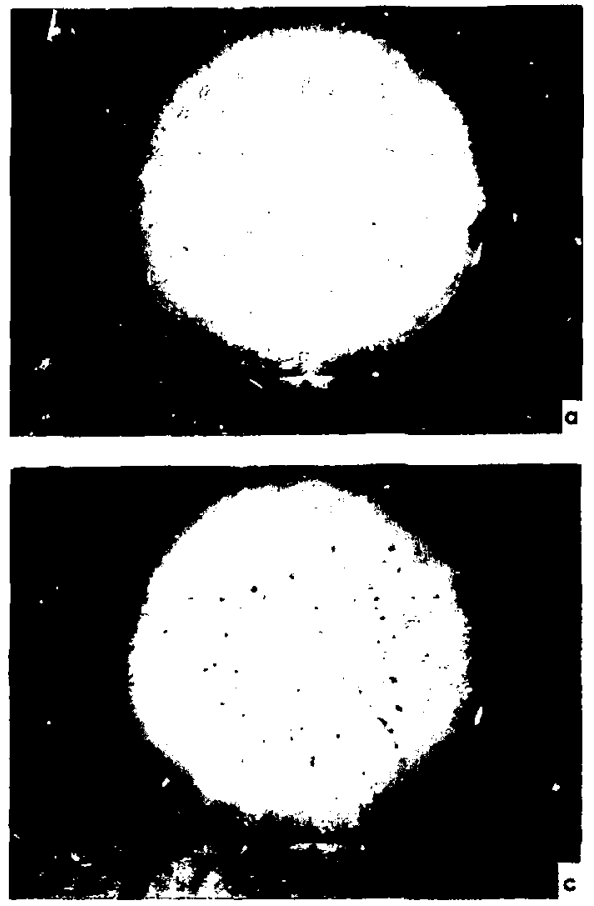

Fig. B. Teflon pellet exposed (a) in air, carbon tetrachloride.

intense main stems, while in the one exposed in the Shell Dialax oil, the main stems are the most intense. Although the main stems do not extend to the outside edge as they did in the lucite pellets, the change in intensicy of the main stems tends to indicate some slectrical communication between the liquids and the samples.

Figure $8 a, b, c$, and $d$ show the results of exposures of Teflon pellets in the same configuration and at the same beam level of $5 \mu \mathrm{C} / \mathrm{cm}^{2}$. The Lichtenberg figures produced in the oil exposure (Fig. 8b) have large diameter and long main stems, while the air exposure (dry)
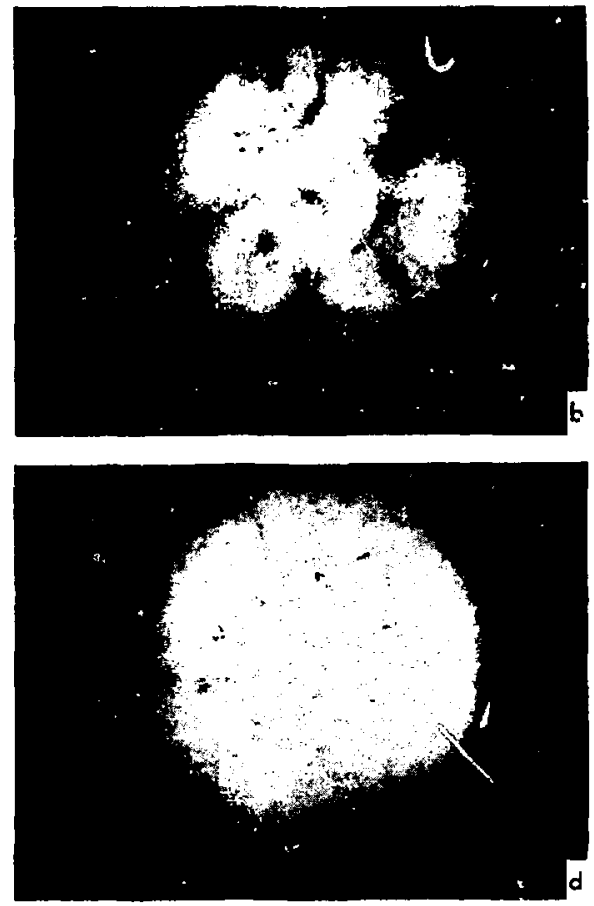

(b) in transformer oil, (c) in alcohol, (d) in shown in Fig. 8a has a large number of small tracks with origins at the back surface of the sample.

Microscopic particles of four different types of dielectric materials were cast in the Shell 815 epoxy and then machined to form pellets of the composite materials that were $2.2 \mathrm{~cm}$ diam $\times 0.6 \mathrm{~cm}$ thick. Glass particles were spherical and of about $10 \mu$ diam and lucite particles were roughly spherical of various sizes ranging up to $50 \mu$ diam. Polyethylene and $T P X$ particles were irregularly shaped and of various dimensions ranging from about 5 to $50 \mu$. These were then exposed to the beam. The materials used were 
type 120 glass beads, $\beta-722$ polyethylene, lucite No. 204D, and methylpentene polymer TPX powder.

Pellets containing glass beads were exposed at $60 \mu \mathrm{C} / \mathrm{cm}^{2}$. Although the $\mathrm{ma}-$ terial separated due to heating, forming an internal crack, we were unable to identify any patterns resembling Lichtenberg figures.

Pellets formed from the polyethylene and lucite both showed some evidence of Lichtenberg figures when exposed to a beam level of $60 \mu \mathrm{C} / \mathrm{cm}^{2}$. However, the track density was low, and where they could be identified, they appeared to be formed primarily in the epoxy material. We saw no evidence of the tracks crossing the boundaries between materials in the matrix. Pellets of pure polyethylene exposed at this level showed quite dense patterns, and pellets of the pure 815 epoxy produced very dense patterns.

Pellets of both of these composite materials (lucite and polyethylene) exposed at a level of $5 \mu \mathrm{C} / \mathrm{cm}^{2}$ showed no evidence of Lichtenberg figures.

\section{High-Speed Photography of Lichtenberg Figures}

In an effort to explore the process of the formation of Lichtenberg figures in some insulating materials, an image converter camera was used in a framing mode to observe the patterns during for- mulation. The setup is shown in Fig. 9. The sample is set up in a holder $10 \mathrm{~cm}$ from the end of the copper screen. Black paper was used on the beam side of the sample to blank off the light due to air

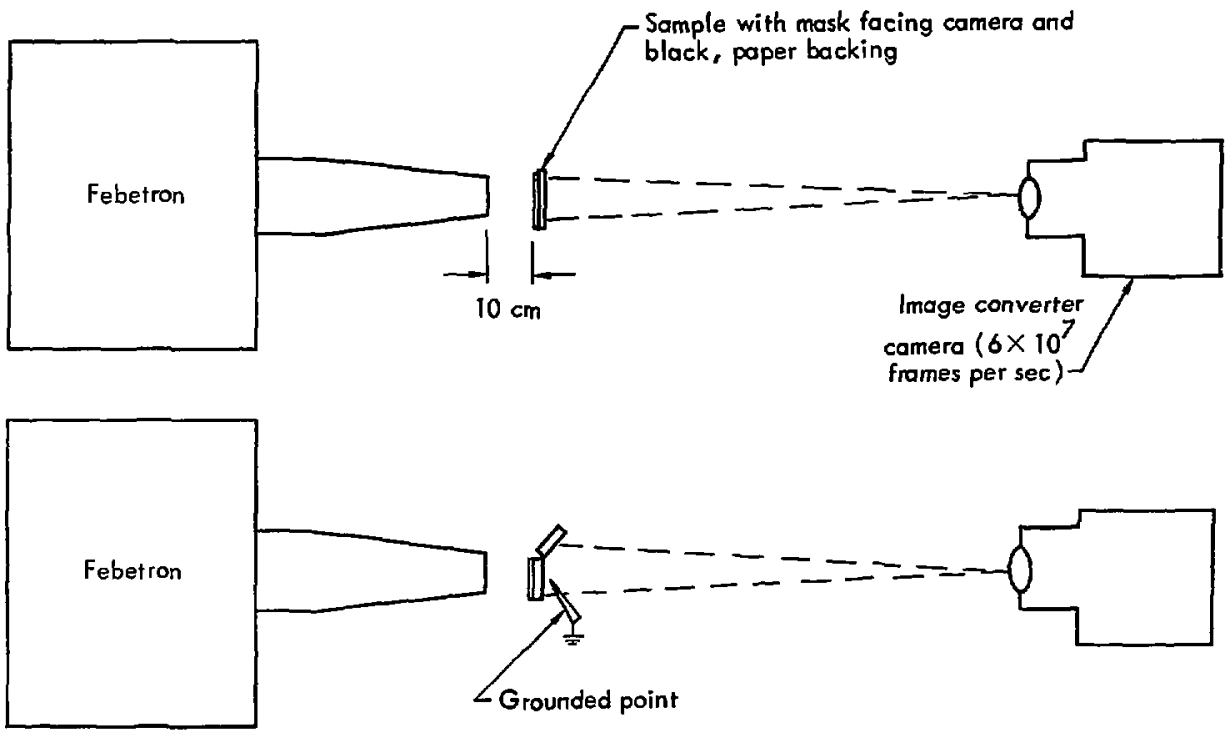

Fig. 9. Setup for high-speed photography. 

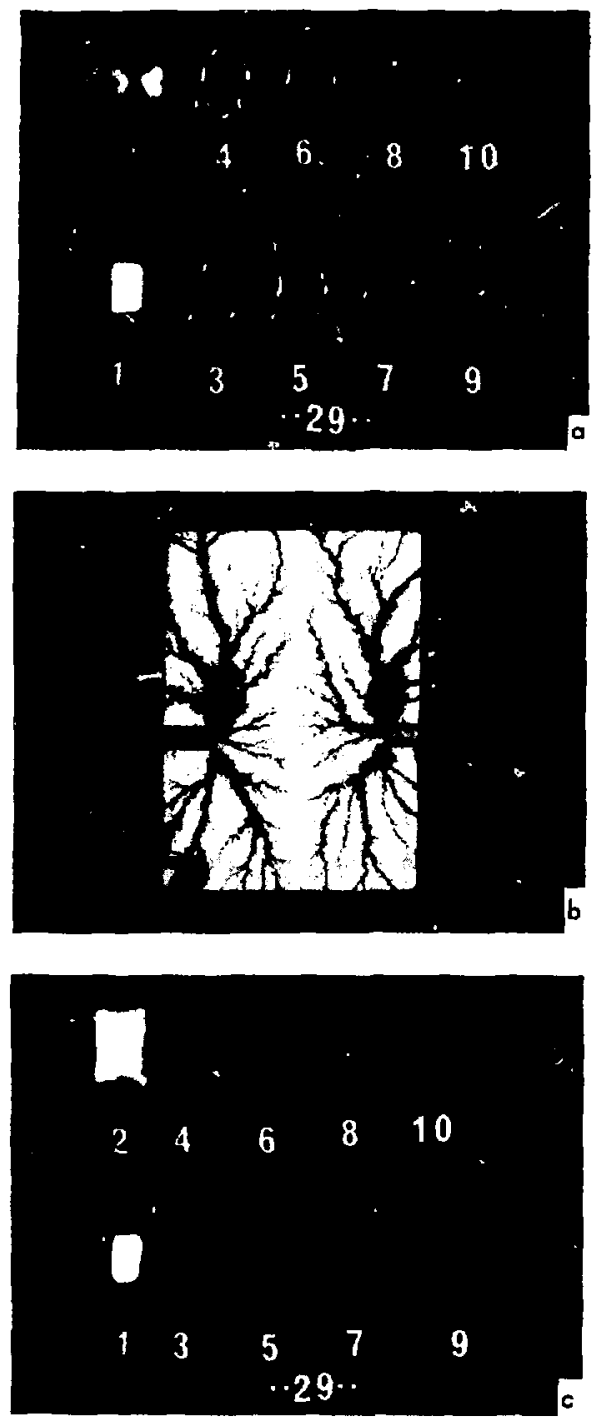

Fig. 10. (a) High-speed framing camera record of Lichtenberg figure formation in lucite sample No. 29 exposed at $2.5 \mu \mathrm{C} / \mathrm{cm}^{2}$. (b) Postexposure photograph of sample No. 29. (c) High-speed framing camera record of sample No. 29 exposed to a second burst at $2.5 \mu \mathrm{C} / \mathrm{cm}^{2}$. ionization. A mask, usually rectangular in shape, was used on the camera side of the sample to define an appropriate field of view for the camera. The camera was used in the framing mode with a framing rate of $6 \times 10^{7}$ frames $/ \mathrm{sec}$, or a $15.5 \mathrm{nsec}$ interframe time. Exposure time for each frame is 3 nsec. Photographs were taken without auxiliary lighting; the event is self-luminous, and we were unable to obtain any enhancement with auxiliary flash-tube lighting.

Sample No. 29 consisted of a block of lucite $7.5 \mathrm{~cm} \times 7.5 \mathrm{~cm} \times 0.6 \mathrm{~cm}$ thick set up for high-speed photography as shown in Fig. 9a. The camera field of view was restricted by the mask to cover an area $2.6 \mathrm{~cm} \times 3.7 \mathrm{~cm}$. Small holes were drilled in the lucite from two opposing edges to define breakdown points. Figure 10a shows the formation of the resultant Lichtenberg figures when the sample was exposed to the Febetron beam at a level of $2.5 \mu \mathrm{C} / \mathrm{cm}^{2}$. The high-speed photographs can be compared with the photograph of the exposed piece of lucite shown in Fig. 10b. In frame one the lucite (or the air) is fluorescing, and in frame two the two patterns have begun to form. In frame three the figures have progressed further, while in frame four they sppear to be fully formed over the viewing area. Between frames 2 and 3 the figure is estimated to have progressed a distance of $1.5 \mathrm{~cm}$ in the $16.5 \mathrm{nsec}$ interframe time, which would indicate a pattern propagation velocity of about $900 \mathrm{~mm} / \mu \mathrm{sec}$. In frames 5 through 10 the pattern continues to nuoresce. We believe that the electrical discharge is continuing throughout this interval. 
Figure $10 \mathrm{c}$ shows the results of exposing the same piece of lucite a second time at the same beam level. Here, in frames 1 and 2 the lucite is fluorescing: by frame 3, the entire pattern is visible. In the remaining frames, the image grows dimmer, receding from the edges towards the two central discharge points.

Figure 11a and $b$ show another example of lucite exposed at $2.5 \mu \mathrm{C} / \mathrm{cm}^{2}$. This sample (No. 41) did not have drilled holes, and the vent to atmosphere occurred on the side facing the camera. Frame 1 shows the lucite fluorescing. In frame 2 the vent to atmosphere is just beginning; by frame 3 the vent has grown considerably and the Lichtenberg figure has probably started to form. By frame 4 the figure is nearly complete. Since the air vent is towards the camera, the plasma continues to glow brightly as it continues through frame 11 . In other samples where the vent is towards the beam side of the sample, the vent point becomes hidden from the camera by the formation of the pattern.

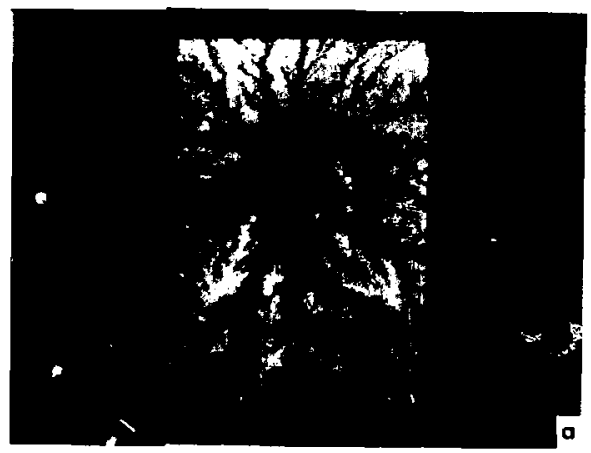

Sample No. 46 (Fig. $12 a$ and b) shows the results of exposure of a lucite sample to a beam level of $1 \mu \mathrm{C} / \mathrm{cm}^{2}$. In frame 3 the large top figure has just started to form, and it continues to grow until frame 9. Based upon the growth rate from frame 4 to frame 8 , the growth rate of the pattern appears to be about $250 \mathrm{~mm} / \mu \mathrm{sec}$; definitely slower than that of sample No. 29, which was exposed at $2.5 \mu \mathrm{C} / \mathrm{cm}^{2}$.

Sample No. 47 (Fig. 13a and b) indicates the results of exposure of lucite to a beam level of $0.6 \mu \mathrm{C} / \mathrm{cm}^{2}$. Here the Lichtenberg figures have just begun to form in frame 4 and the growth may not be completed at the end of the record. From frame 4 to frame 7, the top figure has grown about $4 \mathrm{~mm}$ in $49.5 \mathrm{nsec}$, indicating a propagation velocity of about $80 \mathrm{~mm} / \mu \mathrm{sec}$.

Bright spots have been observed in our photographs when the Lichtenberg figures vent to atmosphere, and the brightness persists for a long time when the vent to atmosphere is towards the

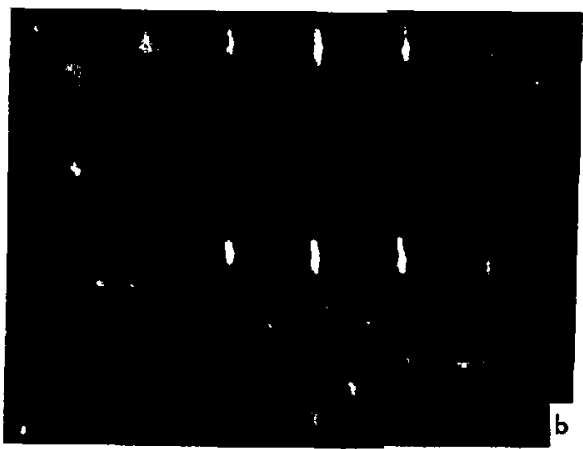

Fig. 11. (a) Postexposure photograph of sample No. 41. (b) High-speed framing camera record of Lichtenberg figure formation in lucite sample No. 41 exposed at $2.5 \mu \mathrm{C} / \mathrm{cm}^{2}$. 

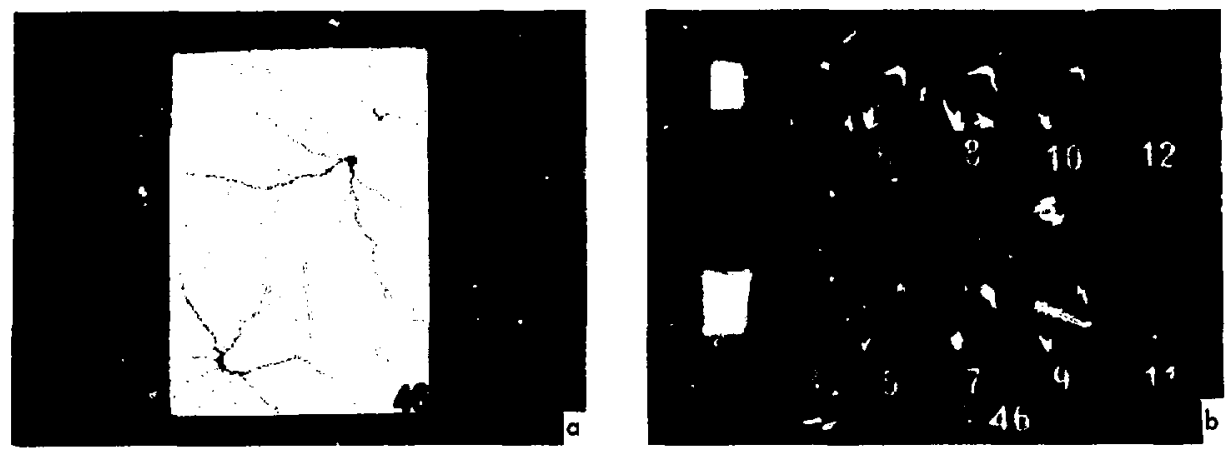

Fig. 12. (a) Postexposure photograph of sample No. 46. (b) High-speed framing camera record of Lichtenberg figure formation in lucite sample No. 46 exposed at $1.0 \mu \mathrm{C} / \mathrm{cm}^{2}$.
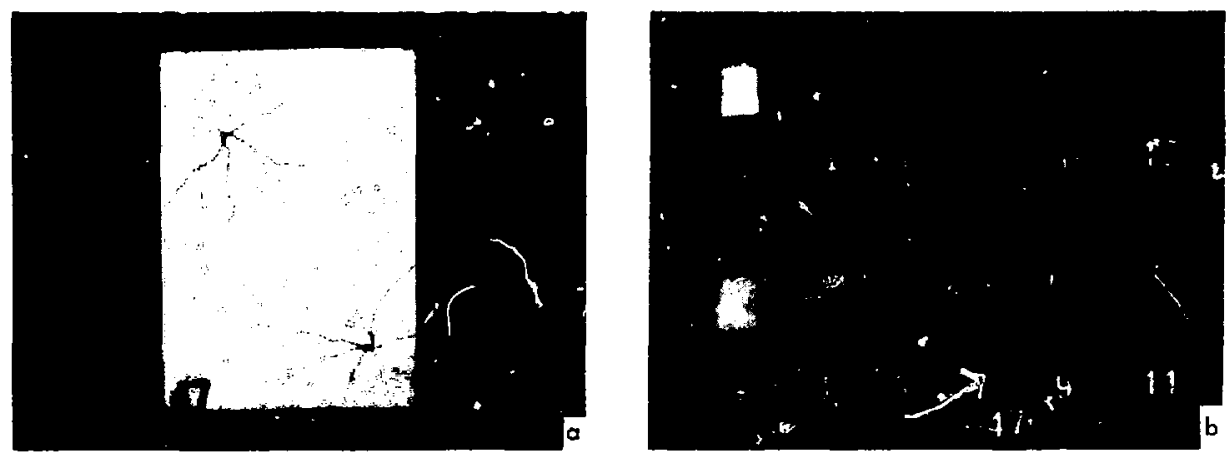

Fig. 13. (a) Postexposure photograph of sample No. 47. (b) High-speed framing camera record of Lichtenberg figure formation in lucite sample No. 47 exposed at $0.6 \mu \mathrm{C} / \mathrm{cm}^{2}$.

camera. To explore this effect further, sample 27 was exposed as shown in Fig. 9b. The sample was shortened at the top so that the imaged portion was only $3.1 \mathrm{~cm}$ high, and top portion of the frame was used to view a mirror at a $45^{\circ}$ angle to the viewing axis. Thus, the top portion of the camera view looks directly parallel to the face of the sample. Figure $14 \mathrm{a}$ and $\mathrm{b}$ show the results of this exposure at a beam level of $2.5 \mu \mathrm{C} / \mathrm{cm}^{2}$.
In frame 1 the beam is seen fluorescing the lucite. In frame 2 the Lichtenberg figure has started to form at the air vent holes and the air ionization between the vent holes and the grounded point located $4 \mathrm{~mm}$ behind them can be seen in the mirror view at the top of the frame. In frame 3 we see that the pattern formation has progressed about $1 \mathrm{~cm}$, indicating a propagation velocity on the order of $1 \mathrm{~cm}$ in $16.5 \mathrm{nsec}$ (or about $600 \mathrm{~mm} / \mu \mathrm{sec}$ ). By 
frame 4 the visible pattern has fully formed; however, the image persists through frame 10. The fact that the plasma persists throughout this same time period may be an indication that the electrical discharge is continuing over a period of at least 8 frames, or about 132 nsec. It should be noted that self illumination due to the discharge along the very fine tendrils of the figure (see photograph of exposed sample) are not visible in the framing camera picture.

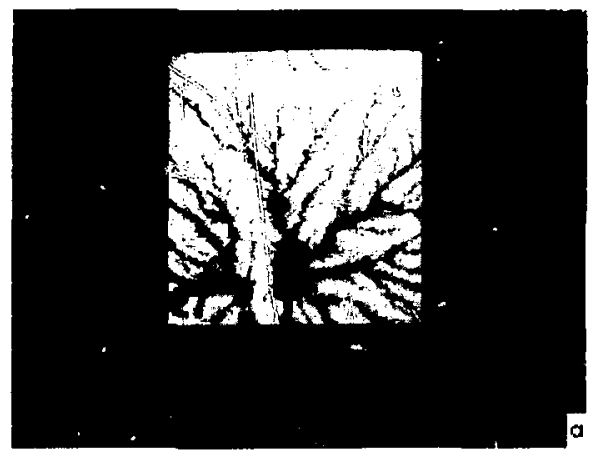

Figure 15a (sample No. 32) show's the Lichtenberg figure formed when vinyl chloride copolymer acetate is exposed to the Febetron beam at a level of $2.5 \mu \mathrm{C} /$ $\mathrm{cm}^{2}$. The material was $3 \mathrm{~mm}$ thick. In fram., 31 and 2 the material is fiuorescing due to the beam. In frame 3 the Lichtenberg figures are partially formed. The figure in the upper right hand corner appears to have progressed far'her at this time than either. of the other two. From this we can infer that, either it

Fig. 14. (a) Postexposure photograph of sample No. 27. (b) High-speed framing camera record of Lichtenberg figure formation in lucite sample No. 27 exposed at $2.5 \mu \mathrm{C} / \mathrm{cm}^{2}$. View at top of frames shows discharge venting to air.
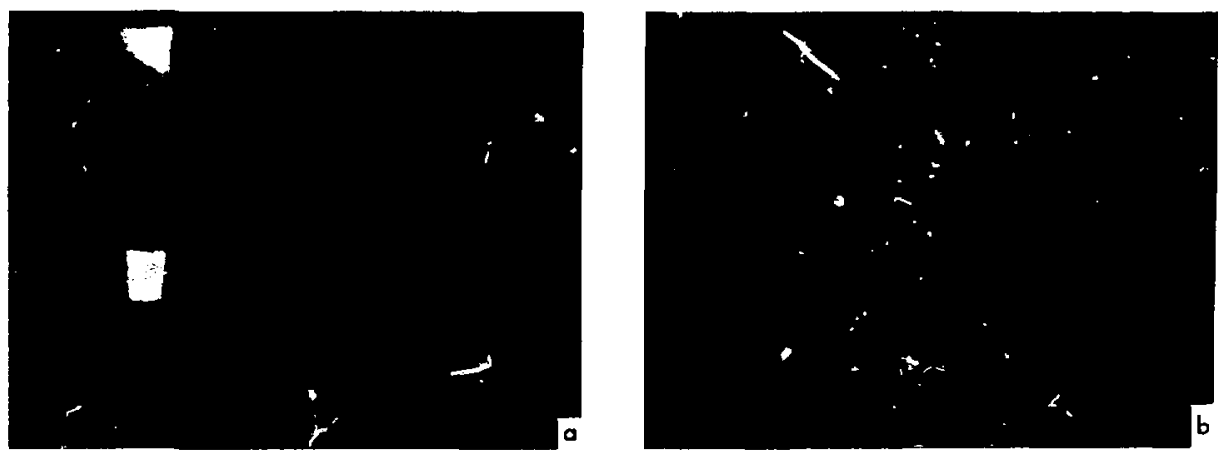

Fig. 15. (a) High-speed framing camera record of Lichtenberg figure formation in vinyl chloride sample No. 32 exposed at $2.5 \mu \mathrm{C} / \mathrm{cr}^{2}$. (b) Postexposure photograph of sample No. 32 . 
formed before the others, or that it is progressing at a faster rate. Upon examination of the photograph of the exposed sample (Fig. 15b) we can observe distinct boundaries between the three main Lichtenburg figures. The lines of the figures do not meet, and the void boundaries are curved, which suggests that the velocities are different. Microscopic examination of the sample indicates that, while a few of the fine lines do cross over those from an adjacent pattern, they do so at different dept'.s in the plastic. It is interesting to nute that near the outer edges of the sample, where the beam intensity is sornewhat less than it is in the center, the lines of the pattern appear to have a preferential direction. This directional sharacteristic seems to be related to the material, and is probably related to stress lines set up during the manufacturing process.

Some estimate of propagation velocity can be made by comparing frame 3 (where the : ttern in the lower right hand corner has progressed about 0.4 of its ultimate length of $17 \mathrm{~mm}$ ) to frame 4. This would
Table 2. Propagation velocities as a function of exposure level for lucite and vinyl chloride.

\begin{tabular}{clcc}
\hline $\begin{array}{c}\text { Sample } \\
\text { No. }\end{array}$ & Material & $\begin{array}{c}\text { Exposure } \\
\text { level } \\
\mu \mathrm{C} / \mathrm{cm}^{2}\end{array}$ & $\begin{array}{c}\text { Propagation } \\
\text { velocity } \\
\text { mm/nsec }\end{array}$ \\
\hline 29 & Lucite & 2.5 & 900 \\
46 & Lucite & 1.0 & 250 \\
47 & Lucite & 0.6 & 80 \\
27 & Lucite & 2.5 & 600 \\
32 & $\begin{array}{l}\text { Vinyl } \\
\text { chloride }\end{array}$ & 2.5 & 600 \\
54 & $\begin{array}{l}\text { Vinyl } \\
\text { chloride }\end{array}$ & 0.6 & 130 \\
\hline
\end{tabular}

indicate a velocity of at least $10 \mathrm{~mm}$ in $16.5 \mathrm{nsec}$, or $600 \mathrm{~mm} / \mu \mathrm{sec}$.

Sample No. 54, also vinyl chloride, was exposed at a reduced beam level of $0.6 \mu \mathrm{C} / \mathrm{cm}^{2}$. Figure $16 \mathrm{a}$ and $\mathrm{b}$ indicate the results of this exposure. In frame 4 the pattern in the lower right hand corner has started to form. From frame 4 to frame 6 the pattern has progressed in a vertical direction about $4.5 \mathrm{~mm}$, indicating a propagation velocity of about $130 \mathrm{~mm} / \mu \mathrm{sec}$. Propagation in the horizontal direction is similar. For this exposure, the pattern was induced to form
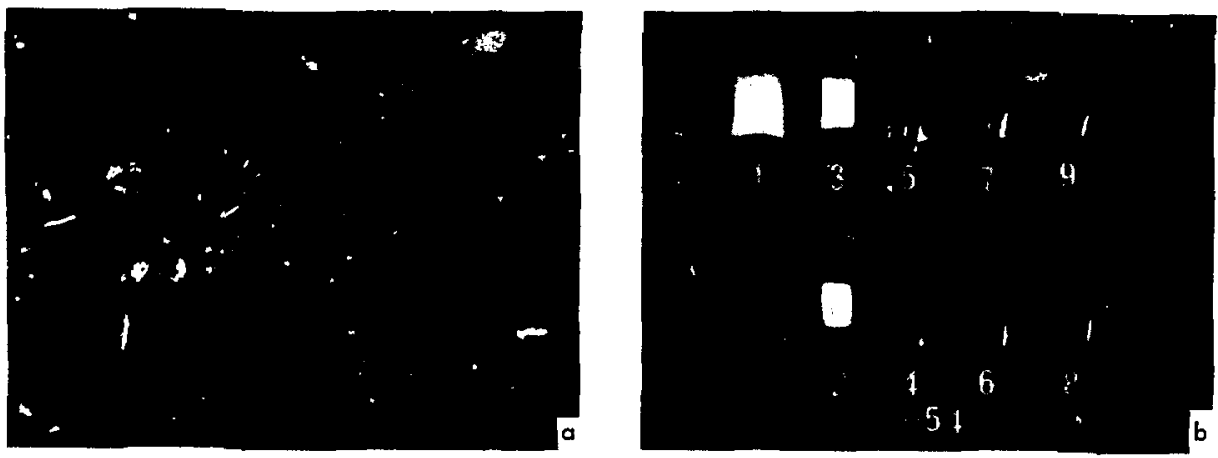

Fig. 16. (a) Pogtexposure photograph of sample No. 54. (b) High-speed framing camera record of Lichtenberg figure formation in vinyl chloride sample No. 54 exposed at $0.6 \mu \mathrm{C} / \mathrm{cm}^{2}$. 

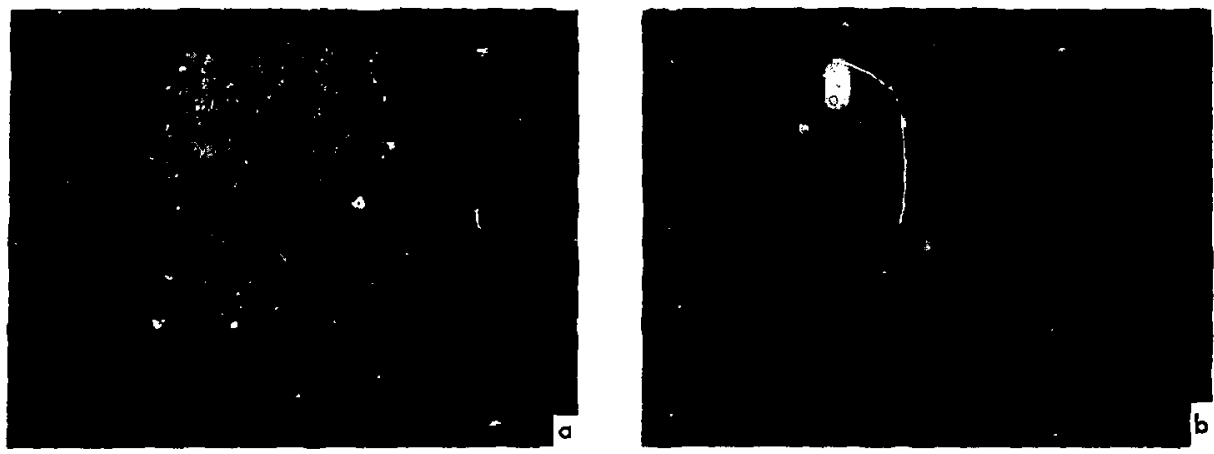

Fig. 17. (a) Postexposure photograph of sample No. 38 . (b) High-speed framing camera record of Lichtenberg figure formation in pyrex glass sample No. 38 exposed to two bursts at $2.5 \mu \mathrm{C} / \mathrm{cm}^{2}$.

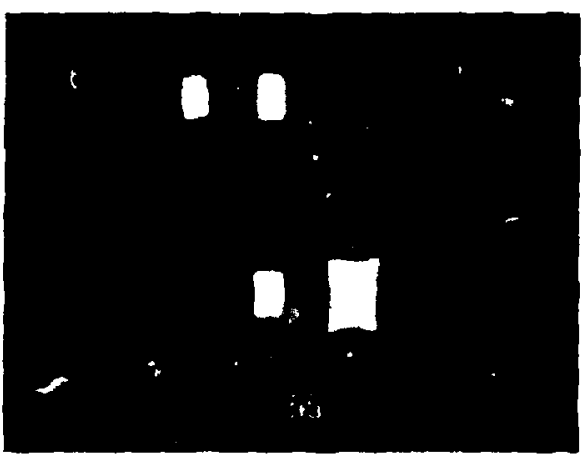

Fig. 18. High-speed framing camera record of fluorescence in quartz glass exposed at $5 \mu \mathrm{C} / \mathrm{cm}^{2}$.

at discreet points by lightly prepunching the material with a sharp-pointed punch.

Table 2 lists the measurements of propagation velocities as a function of exposure level for lucite and vinyl chloride.

Sample No, 38 was of pyrex glass (3.25 $\mathrm{mm}$ thick) and the results of its exposure are shown in Fig. $17 a$ and $b$. Two Febetron pulses at $2.5 \mu \mathrm{C} / \mathrm{cm}^{2}$ were required to produce the Lichtenberg fig- ure. Vents to the atmosphere faced the camera resulting in plasma that provides some difficulty in measuring propagation velocity of the figure, but by frame 2 the pattern in the upper left hand corner has grown to nearly its full length of over $20 \mathrm{~mm}$. It may have been partly formed in frame 1 but is not visible due to beam fluorescence, so the growth rate is greater than $20 \mathrm{~mm}$ in two frames or, greater than $600 \mathrm{~mm} / \mathrm{nsec}$. Pattern formation in pyrex is rather unpradictable under these exposure conditions. Several pieces were exposed in which the pattern formed long after the exposure. In one case we walked into the room after the burst and the pattern formed while we were present.

We were unable to form a pattern in borosilìcate glass or in $\mathrm{g}^{\mathbf{i}}$. $\mathrm{rtz}$ at a beam level of $5 \mu \mathrm{C} / \mathrm{cm}^{2}$, even with several Febetron pulses. Sample 55 was of quartz plate, $3 \mathrm{~mm}$ thick, and Fig. 18 shows the fluorescent pattern due to the beam. Note that it persists for four frames, or at least 66 nsec. Flourescence of the beam in lucite does not 

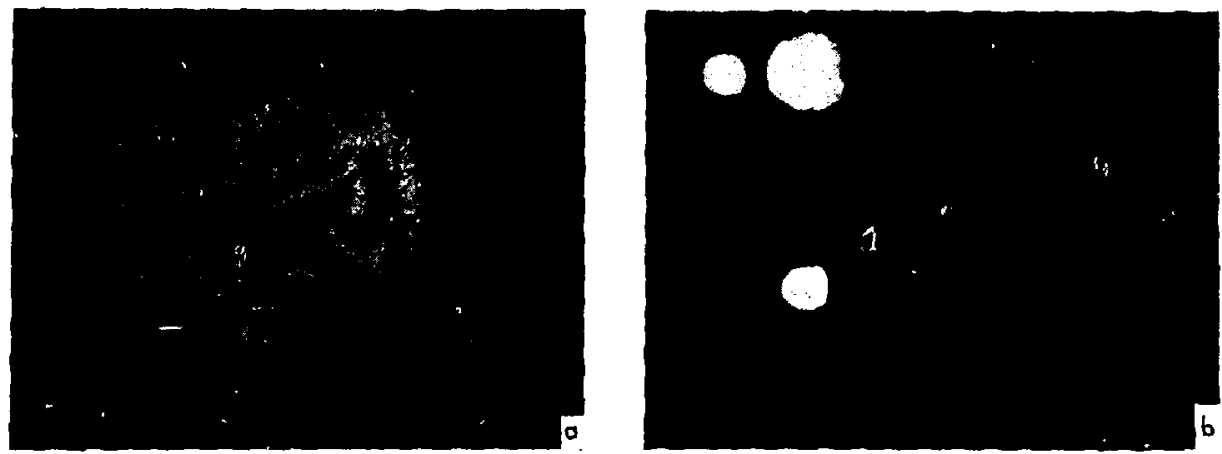

Fig. 19. (a) Postexposure photograph of sample No. 39. (b) High-speed framing camera record of Lichtenberg figure formation in Viton A sample No. 39 exposed at $2.5 \mu \mathrm{C} / \mathrm{cm}^{2}$.

generally persist this long, sometimes only half as long. However, photographs of lucite were only taken at half or less than half of this beam intensity.

Sample No. 39 was a pellet of Viton A. It was $2.3 \mathrm{~cm}$ in diameter, and $6 \mathrm{~mm}$ thick. It was pressed into a hole in a polyethylene holder and exposed at a level of $2.5 \mu \mathrm{C} / \mathrm{cm}^{2}$. Figure $19 \mathrm{a}$ and $\mathrm{b}$ shows the results of this exposure. In frame 3 the Viton is still fluorescing due to the Febetron beam; however it looks as though the Lichtenberg figures are also in the process of formation. By frame 4 the figure appears to be fully formed; however, it is difficult to tell for sure since the surface condition of the material did not lend itself to the best photography. There is also some frame overlap in the pictures.

\section{Conclusions-Summary}

In the materials we studied (lucite, polyethylene, teflon, and nylon) Lichtenberg figures are formed at about the same threshold of $1 \mu \mathrm{C} / \mathrm{cm}^{2}$ of electrons from the $2.1 \mathrm{MeV}$ Febetron. Threshold for lucite is slightly higher than the others. As the beam level is increased beyond threshold the intensity of the main stems of the patterns increases over the ranges we studied. However, this effect is more pronounced in lucite than in the other three materials.
In lucite the patterns formed in small pellets indicate less energy release through the main stems of the tracks than in the larger ones for a given beam level. Accordingly, the threshold for forming Lichtenberg figures is somewhat dependent on the area over which the electrons are deposited in the material; no pattern was formed in $0.3-\mathrm{cm}$ diam pellets at $2.5 \mu \mathrm{C} / \mathrm{cm}^{2}$, but they did form in all the iarger diameter pellets. Smaller pellets $(2.5 \mathrm{~mm}$ cubes $)$ 
sometimes formed patterns at a beam level of $5 \mu \mathrm{C} / \mathrm{cm}^{2}$.

In some cases there appears to be an increase in the density of the main stems of the patterns formed when they are exposea in a bath of liquid dielectric. In particular, with Shell Dialax transformer oil there appears to be some communication of electrons stopped in the liquid through the main stems of the discharge paths in the solid materials.

It appears to be much more difficult to form Lichtenberg figures in insulators that are made of composites of small particles of two dielectric materials. When the figures are formed in the mate- rials we studied they tend to be confined to one material or the other. In the case of the $2.5 \mathrm{~cm}^{3}$ lucite pellets cast in epoxy, figures are formed in both materials, but we could see no indication of patterns crossing the boundaries between insulators. Rather, the figures tend to end at the boundaries.

High-speed photographs were taken of the formation of Lichtenherg figures in several transparent materials and some propagation velocities were measured. For a given insulator, propagation velocity varies as a function of exposure level when electrons are injected with the pulaed Febetron beam.

\section{Acknowledgments}

Thanks to John Woodruff for the ETRAN calculatione and to Terry Ramos for his help in conducting the experiments. 